\title{
A Review of Economic Policy Uncertainty
}

\author{
Zeyu Chen ${ }^{1, *, a, \dagger}$, Yunqi Ma ${ }^{2, b, \dagger}$, Yuansen $\mathrm{Xia}^{3, \mathrm{c}, \dagger}$ \\ ${ }^{1}$ Nord Anglia Chinese International School,Shanghai,Fuzhou, China \\ ${ }^{2}$ Nanchang No. 2 High School,Nanchang, China \\ ${ }^{3}$ University of Illinois at Urbana Champaign,Shanghai, China \\ *Corresponding author.Email:azeyu.chen@mynbps.org, ${ }^{\text {*MaeveMa@gmail.com, }{ }^{c} x i a y u a n s e n 2002 @ i c l o u d . c o m}$
}

\begin{abstract}
This paper reviews the research on the economic policy uncertainty (EPU). Measurement of EPU is first brought up by Nick Bloom and his co-authors and then has been widely generalized and applied in the empirical studies. We survey the literature on both the construction of the EPU proxies and the impacts of EPU on the economy.
\end{abstract}

Keywords: Economic policy uncertainty, policy uncertainty, corporate investment

\section{INTRODUCTION}

Combined with the development of the world economic market, and people are living in a better life. At the same time, the progress of science and technology also drives the birth of new markets. People began to pay more attention to the global economic market, where the Economic Policy Uncertainty (EPU) began to receive more attention and more weight due to the entry of new markets. This is important for businesses and emerging markets, because they will be affected by different policies, both good and bad. Shareholders or investors can also invest or sell according to the EPU. The EPU is crucial to market stability. Furthermore, the economic policy uncertainty index is mainly used to reflect the economic and policy uncertainty of major economies in the world. Also, EPU index has a significant inverse relationship with real macroeconomic variables (such as economic growth and employment), and can even explain the violent fluctuations of the stock market. We found that the literature is divided into two parts: one mainly studies how to measure EPU, and the other studies the impact of EPU. (2) The first literature, in measuring EPU, mainly used theoretical method and a little bit index. It shows the clearly abstract of EPU. (3) In the second literature, the influence is divided into several aspects, which is the negative influence and positive effect.

The rest of this paper is organized as follows. Section 2 reviews the background of economic policy uncertainty in terms of definitions and measurements.
Section 3 presents the influence of economic policy uncertainty. Section 4 concludes.

\section{CONSTRUCTION OF EPU INDEX}

The EPU index can be used as a measure of shortterm general sentiment, such as volatility and uncertainty in European trade.

First of all, we need to know which parts the EPU index is divided into. The EPU index is divided into three parts. The first part is the news index, which is collected through the articles related to the analysis of economic policy uncertainties of several large newspapers. The second section is the invalidation index, which is a measure of uncertainty based on the number of invalidations each year. The third part is the index of economic forecast difference. These three components are all good ways to measure EPU. It is also possible to fill the liability side of the holding balance with an appropriate amount of equity based on movement, from the point of view of assets held. The closing balance of the EPU is calculated as the sum of the moving and opening balances. The above example shows the basis of the EPU calculation [1].

In some papers, the main method is to analyze policy choices. For example, in an article, China's EPU in 2008 was analyzed. There were several large spikes in this chart, which turned into inflationary pressures through the subprime crisis. Through the example of the change of government, national debt crisis impact on the point of national internal economy to prove [2]. 
What is particularly interesting is that the EPU index of the United States is different from that of other countries. The EPU index of the United States is divided into three parts, which are the three parts mentioned above. The EPU measurement methods of China and Europe are verified by the news index in the first part. After analyzing relevant articles, the EPU index is obtained by some methods. For example, the advantage of obtaining EPU only through news index is that the news index has a strong correlation with the comprehensive index through statistics and labeling processing. The difference of the EPU index in Europe and America is related to the US dollar index. The EPU index in China is positively correlated with the bond market, but negatively correlated with the stock market. Then we can talk about the impact of the EPU index on various aspects. First of all, in the case of high economic policy uncertainty, it is very bad for many enterprises and will delay the progress of enterprise investment. Because in the case of unstable economic policy, it will bring great risks and instability to enterprise investment, so many enterprises will wait and see for a long time.

The second is that the uncertainty of economic policy will stimulate people's irrational emotions and affect people's investment behavior. In one of the articles I found, EPU had a huge impact on everything. The index of overall EPU height will be very easy to affect the country's economic situation, will affect people's life and the way of investment. EPU index will also affect the interests among nations, such as trade, etc. EPU will also affect the national government's decision-making, is to choose what kind of choice way to get the maximum benefit. It will have a huge impact on the economic side of many businesses.

\section{THE INFLUENCE OF EPU}

\subsection{Mainstream Views and Analysis}

Most researchers argue that EPU has negative influence on enterprises' activities economically. Yajun Zhang studied the manufacturing companies listed on the main board of Shanghai and Shenzhen stock exchanges as the research object and took China's economic policy uncertainty index as the measurement index of economic policy uncertainty. The author found that EPU has negative influence on investment, which is irreversible, and the higher the debt ratio is, the severer the influence is to a company. [1] Additionally, it also shows that EPU has negative impact on contract, which may rise the possibility of inability to implement the contract through analyzing the annual data of relevant variables from 2012 to 2017 to conduct an empirical study to examine the impact of economic policy uncertainty on default risk [2] Hui Gu takes the quarterly data of Shanghai and Shenzhen A-share listed companies from 2003 to 2017 as the research sample, and takes the uncertainty index of China's economic policy compiled by Baker et al. (2016) as the index to measure the uncertainty of China's economic policy Through empirical analysis, the following conclusions shows that EPU has negative influence on enterprise's asset, but with the change of exchange rate, this influence reduces gradually. [3] It also shows that EPU has directly negative relation with assets of enterprises in long run. [4] Most importantly, Yihan Zhang and Chuming Wang analyze A-share listed companies in Shanghai and Shenzhen from 2010 to 2019 as samples, uses fixed effect model to study the impact of economic policy uncertainty on enterprise risk-taking and the intermediary effect of leverage ratio, and analyzes the relationship among economic policy uncertainty, leverage ratio and enterprise risk-taking. Finally, they declare that EPU is more negatively influential to small companies comparing to enterprises.[5] Similarly, Deng Meiwei also says that the stronger the company is, the less negative influence it receives. [6] In addition, Caldara et al. claim that EPU has negative influences on investment and trading activities byThree measures of TPU are constructed using newspaper coverage, firms' earnings calls, and tariff rates. Firm-level and aggregate macroeconomic data reveal that increases in TPU reduce business investment. [7] If EPU is too high, enterprises will face the situation of high debt ratio, while if that is too low, and EPU is an important risk factor of equities.[8] Also, Dazhong Wang et al. declare that EPU influences leverage ratios of enterprises negatively.[9]

\subsection{Another Perspective and Evidence}

On the other hand, it shows that EPU has beneficial aspects. Ying sun studies, based on the data of China's listed companies from 2007 to 2017 and China's economic policy uncertainty index constructed by Baker, the impact of economic policy uncertainty on investment. The result indicates that EPU has positive impact on innovation, and this impact is caused by some other reasons besides EPU. [10] Moreover, EPU can motivate enterprises to invent new technologies positively, [11] and it also has a positive influence on innovation of companies with relatively small amount of assets, while it has detrimental impact on enterprises with large amount of assets. Ji Wang concludes that based on previous studies. He expounds how the uncertainty of economic policy will affect the R \& D investment of enterprises. Due to the real option theory, enterprises will regard $\mathrm{R} \& \mathrm{D}$ achievements as an option, so as to increase $\mathrm{R} \& \mathrm{D}$ investment when economic uncertainty rises, hoping to gain competitive advantage through innovation. Therefore, economic policy uncertainty has an incentive effect on $R$ \& D investment. In addition, due to information asymmetry, financing constraints can adjust the impact of economic policy uncertainty on enterprises, and economic policy uncertainty has different effects on enterprises receiving 
different amounts of government subsidies. On the basis of theoretical analysis, he takes the data of listed enterprises from 2011 to 2018 as the research object, from the perspective of enterprise $\mathrm{R}$ \&amp; D investment, uses the fixed effect model to analyze the impact of economic policy uncertainty on enterprise innovation, and further tests the regulatory effect of financing constraints and government subsidies.[12]Deng Meiwei studies the panel data of China's A-share non-financial listed companies from 2011 to 2017 , and empirically discusses the impact of economic policy uncertainty on corporate performance. The result indicates that though the effects of EPU cannot be seen immediately in the short run, it has positive effects in the long run.[13]

\subsection{Supplement}

What is more, from a border perspective, EPU has impacts other factors as well.

Kang Wensheng and Wang Jing find that EPU has negative influence on corporate tax with direct relation. Also other policies' impact on other rates. They draw the conclusion by showing consistent results that corporate cash tax burden within a year rises when economic policy uncertainty heightens using aggregate-level data. Time-varying tax effects of policy uncertainty are gradual and take time to induce corporate precautionary motives to engage in cash tax saving in the long run. Firm-level analysis confirms that the tax effects of policy uncertainty are asymmetric and depend on underlying sources of monetary/fiscal policy uncertainty. [14] Also, Baker Scott R et al. develop a new index of economic policy uncertainty based on newspaper coverage frequency. Several types of evidence-including human readings of 12,000 newspaper articles-indicate that our index proxies for movements in policy-related economic uncertainty. They conclude that EPU makes stock prices have higher volatility, and also impacts investment and employment rate in a negative way.[15]Similarly, Chu Jian and Fang Junxiong declare that EUP has negative influence on employment rate but being beneficial to labor investment efficiency.They draw the conclusion by using Economic Policy Uncertainty Index for China and Chinese A-share listed firms in the period 2002-2016 to constructs a sample of 20,779 firm-year observations and applies the methods of pooled OLS regressions to do an empirical study.[16] Moreover, Gu Ming et.al show that a news-based measure of economic policy uncertainty (EPU) negatively forecasts momentum. A 1standard-deviation increase in EPU is associated with a $1.11 \%$ decrease in risk-adjusted momentum returns. The predictive power of EPU is robust after controlling for previously documented economic state variables and macroeconomic uncertainty. They also provide an explanation for these results from the perspective of a fund flow-induced trading mechanism and offer direct empirical support. The literature documents that momentum can be partially attributed to performancechasing mutual fund flows. They discover that EPU has negative influence to momentum from decreasing riskadjusted momentum returns, etc.[17] Also, EPU has negative impact on economic activities with different levels in different historical background. Creal Drew D and $\mathrm{Wu}$ Jing Cynthia investigate The relationship between the uncertainty of monetary policy and its transmission mechanism and economic fluctuation. They proposed a new term structure model, in which the second moment of macroeconomic variables and returns can have a first-order effect on its dynamics. These data support a model with two unprocessed volatility factors that capture the uncertainty of monetary policy and term premium.[18] Qingfu Meng and Qian Shi declare that Macroeconomic policies can motivate companies to innovate and gain huge profits. [19]Moreover, Jieyuan Jiang demonstrates that government decisions may influence future economy structure.[20]

\subsection{Special Case}

Nonetheless, there are special cases found that EPU has relatively small impact on economy. In Russia, EUP does not has impact on public companies, but negatively on European and global economy. Naidenova and Vernoika gain the conclusion by applying fixed effects models on panel data, in which the effect model is most pronounced for large companies [21]. Liu et al. investigate the data of 52 traditional energy enterprises and 116 renewable energy enterprises of China from 2007Q1 to 2017Q4, they concluded that EPU has relatively less obvious impact on New-Energy Company comparing to traditional companies [22].

\section{CONCLUSION}

In conclusion, EPU has both positive and negative influence on economy to different levels, depending on many factors including the firm size. However, Russia has relatively small influence by that comparing to other countries in the world. In the future, it is believed that enterprises need to come up with effective strategies to minimize the loss caused by EPU. Also, official authorities should also devote themselves to render EPU to be an effective aid to develop economy more than being harmful to domestic enterprises.

\section{REFERENCES}

[1] Saud Asaad Al-Thaqeb,Barrak Ghanim Algharabali. Economic policy uncertainty: A literature review $[\mathrm{J}]$. The Journal of Economic Asymmetries,2019,20.

[2] Jintao Wang,Yijin Zheng. Economic policy uncertainty and grain prices volatility $[\mathrm{J}]$. The 
Frontiers of Society, Science and Technology,2019,1(10).

[3] Yong Jiang,Zhongbao Zhou,Cenjie Liu. Does economic policy uncertainty matter for carbon emission? Evidence from US sector level data[J]. Environmental Science and Pollution Research,2019,26(24).

[4] Chen "It also shows that EPU has directly negative relation with assets of enterprises in long run.'.

[5] Li,Ma,Zhang,Xiao. Economic policy uncertainty and the Chinese stock market volatility: new evidence[J]. Applied Economics,2019,51(49).

[6] Peng Liu,Daxin Dong. Impact of Economic Policy Uncertainty on Trade Credit Provision: The Role of Social Trust[J]. Sustainability,2020,12(4).

[7] Sagi Akron,Ender Demir,José María DíezEsteban,Conrado Diego García-Gómez. Economic policy uncertainty and corporate investment: Evidence from the U.S. hospitality industry[J]. Tourism Management,2020,77.

[8] Brogaard J, Detzel A L . The Asset Pricing Implications of Government Economic Policy Uncertainty[J]. Social Science Electronic Publishing.

[9] Wang et al. "declare that EPU influences leverage ratios...".

[10] Ying sun "based on the data of China's listed companies from 2007 to 2017 ".

[11] Yu Jian,Shi Xunpeng,Guo Dongmei,Yang Longjian. Economic policy uncertainty (EPU) and firm carbon emissions: Evidence using a China provincial EPU index[J]. Energy Economics,2021,94.

[12] Pastor L, Veronesi P. Uncertainty about Government Policy and Stock Prices[J]. Journal of Finance, 2012.

[13] Qinwei Chi,Wenjing Li.Economic policy uncertainty, credit risks and banks lending decisions: Evidence from Chinese commercial banks[J].China Journal of Accounting Research,2017,10(01):33-50.

[14] Kang and Wang "found that EPU has negative influence on corporate tax".

[15] Baker S R, Bloom N, Davis S J. Measuring economic policy uncertainty[J]. LSE Research Online Documents on Economics, 2015.

[16] Chu and Fang "declare that EUP has negative influence...”.
[17] $\mathrm{Gu}$ et.al discover "that EPU has negative influence..."

[18]Ji (George) Wu,Jian Zhang,Yiwen Wu,Dongmin Kong. When to go abroad: economic policy uncertainty and Chinese firms' overseas investment[J]. Accounting \& Finance,2020,60(2).

[19] Meng and Shi "declare that Macroeconomic policies...".

[20] Han,Qi,Yin. Macroeconomic policy uncertainty shocks on the Chinese economy: a GVAR analysis[J]. Applied Economics,2016,48(51).

[21] Naidenova I.N., Leonteva V.V. Economic policy uncertainty and investment of Russian companies. Voprosy Ekonomiki. 2020;(2):141-159.

[22] Li Liu,Tao Zhang. Economic policy uncertainty and stock market volatility[J]. Finance Research Letters,2015,15.

[23] Guo. The Impact of Economic Policy Uncertainty on Macroeconomy and Its Regional Differences: An Analysis of PVAR Model Based on Provincial Panel Data [J]. Science of finance and economics.

[24] Zhong. Economic Policy Uncertainty and Financial Stability: A Literature Review [J]. Yuejiang Academic Journal.

[25] Ling. Does economic policy uncertainty have both output and inflation effects? -- Empirical Evidence from China [J]. Nankai Economic Research. 